the author's career in scientific politics, his Nobel prize and other honours - "I soon learned that one wins awards mainly for winning awards" - and various foreign adventures, including a memorable visit to Beijing that coincided with the Tiananmen Square uprising, thus flouting his newly enunciated travel theorem:

Anything that can be learned by a normal American adult on a trip to a foreign country (of less than one year's duration) can be learned more quickly, cheaply and easily by visiting the San Diego Public Library.

(My own travel theorem states that most of the world's troubles arise from people visiting places where they do not belong and interfering in matters that are not their business.)

The book is a mine of shrewd observations: on the need of students for their teachers' affection, and vice versa; on the roles of analysis and synthesis in science the latter much neglected; on the inexactness of the 'exact' sciences, at least in their application to practical problems, and on a common stumbling-block to interdisciplinary research:

\section{Nature or nurture}

Peter Bryant

The Origins of Exceptional Abilities. By Michael J. A. Howe. Blackwell: 1990. Pp.262. £35, \$39.95.

THE lives and achievements of talented people raise some interesting questions for psychologists, who would like to know the reasons for their extraordinary skills and would also like to find out if it is possible to teach more people to be gifted. These two questions are related, of course: if gifted people acquire their talents because of the experiences that they had during their childhood, it ought to be possible to provide other children with the same kind of experiences. The trouble is that it is usually very difficult to work out what are the causes of each gifted person's great success. Many gifted people work extremely hard at practising and improving their talents, and often, as children, receive a great deal of encouragement to do so from their parents and teachers. But we usually cannot tell whether these apparently propitious circumstances are the cause or the result of the person's talent. The young Mozart, for example, practised his music a great deal and he received much coaching from his father, but he also came from a musical family and it is quite possible that genetic factors played a considerable part in his extraordinary talents. It is also possible that he worked as hard as he did and received so much attention and encouragement because, for genetically determined reasons, he was unusually talented. We have no way of disentangling cause and effect.
I would not give a dollar to assist a typical political scientist to collaborate with a typical economist unless each one of them gave me a sworn statement that he would study seriously.... the discipline of the other for at least a year.

As a historical document, the autobiography covers a period of astonishing intellectual ferment: the explosion of the information sciences after the Second World War, the resulting transformation of psychology by the information processing paradigm and the use of computer simulation for getting a grip on the behaviour of highly complex systems. Particularly welcome is Simon's support for the view that one working AI program is worth a hundred opinionated articles on the powers and limitations of machines or networks of one kind or another.

Models of My Life achieves most admirably the goal of the Sloan Foundation to "make the scientific experience and the excitement of discovery accessible to the general reader."

$H$. Christopher Longuet-Higgins is at the Laboratory of Experimental Psychology, University of Sussex, Brighton BN1 9QG, UK.

This means that anyone who sets out to convince us that the reasons for exceptional talents are environmental ones has a difficult task on his or her hands. Yet this is the position that Michael Howe adopts in The Origins of Exceptional Abilities. He does acknowledge from time to time that it is difficult to prove that the particular circumstances in which Darwin, Mozart, Sir Richard Burton and several others were brought up were responsible for their remarkable gifts, but he seems to be sure that the environmental explanation is the correct one. He writes,

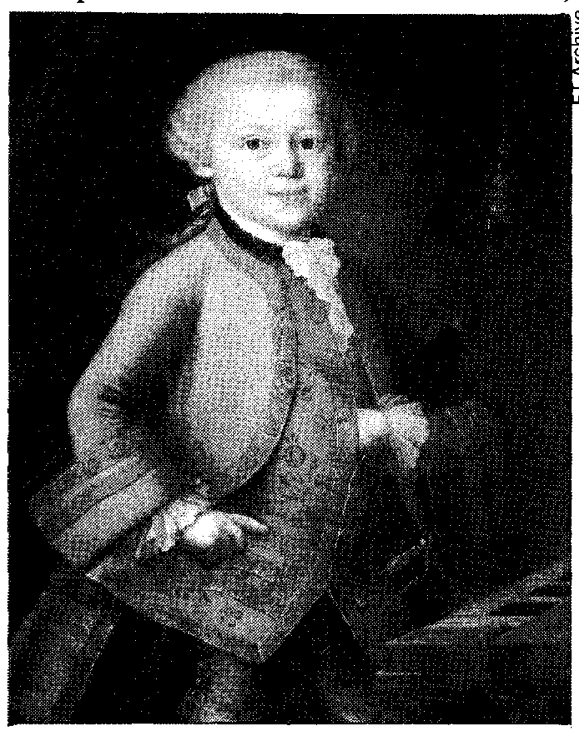

The child Mozart - was he born great or was greatness thrust upon him?

or course, at some length about the lives of these individuals and of several other people with exceptional talents, but he also marshals research on ordinary people to support his case.
His argument about the lives and particularly the childhood of exceptional people is unconvincing. His claim that they lived in unusual environments and had unusual experiences could only have any weight if it could be shown to be true. But we cannot rule out the possibility that other, less successful people were brought up in similar circumstances, and even if that were certain we would still have the chicken-and-egg problem of being uncertain whether the circumstances caused the talent or vice versa. The life histories of these extraordinary people always makes interesting reading, and they form the more interesting part of Howe's book, but the stories are not new and their relevance to our notions of intelligence have been discussed in more detail in books by Gruber, Gardner, Feldman and Treffert.

The work that Howe reviews on ordinary people is in the end no more persuasive. His main concern is to show that it is possible to influence people's skills by changing their experiences. Children, he argues, can be taught to read earlier, their motor skills can be improved, and their acquisition of language can be enhanced. All this is true but it has no obvious bearing on people with exceptional talents. Successful programmes for teaching reading do not produce exceptional readers - just children who can read. At times too, Howe seems to treat other people's views as hard evidence, provided that he shares those views. For example, he states that "Vygotsky showed that human cultures, internalised by children largely through the mediation of social interactions, not only provide access to skills and knowledge but also determine the fundamental sign systems that underlie knowledge". This is certainly what the Russian psychologist thought to be the case, but he never 'showed' that his theory was right, and in fact did very little in the way of empirical research.

Howe's charitable assessment of those who take the same position as his own contrasts strongly with his approach to other views with which he disagrees. "Far too often", he writes, "people have accepted uncritically beliefs about the importance of this or that factor simply because they seem plausible, or appear to be true or are widely considered by others to be true." But, disappointingly, he does not go on to identify these 'people' or to tell us exactly what their uncritical beliefs are.

The Origin of Exceptional Abilities raises an important and interesting question and provides a firm, but in the end quite unconvincing, answer. In fact no definite answer is possible at the moment. Until one is, we will need, and we still have to wait for, a fair and reasoned account of the evidence for and against all the plausible hypotheses about the reasons why some people acquire astonishing talents and the rest of us do not.

Peter Bryant is in the Department of Experimental Psychology, South Parks Road, OXford OX1 3UD, UK 